\title{
The impact of COVID-19 on contraception and abortion care policy and practice: experiences from selected countries
}

\author{
Deborah J Bateson (D) , 1,2 Patricia A Lohr (D) , Wendy V Norman (D) , ${ }^{3,5}$ \\ Caroline Moreau (D) ,6,7 Kristina Gemzell-Danielsson, 8,9 \\ Paul D Blumenthal, ${ }^{10}$ Lesley Hoggart (D), ${ }^{11}$ Hang-Wun Raymond Li (D) , ${ }^{12}$ \\ Abigail R A Aiken, ${ }^{13}$ Kirsten I Black (D) 2,14
}

For numbered affiliations see end of article.

\section{Correspondence to} Professor Deborah J Bateson, Family Planning New South Wales, Sydney, NSW 2131, Australia; deborahb@fpnsw. org.au

Received 24 May 2020 Revised 21 July 2020 Accepted 28 July 2020 Published Online First 11 August 2020

\section{Check for updates}

(c) Author(s) (or their employer(s)) 2020. No commercial re-use. See rights and permissions. Published by BMJ.

To cite: Bateson DJ, Lohr PA, Norman WV, et al. BMJ Sex Reprod Health 2020;46:241-243.
No area of healthcare is immune to the impact of COVID-19. The pandemic will affect sexual and reproductive health (SRH) worldwide in positive and negative ways. Home isolation and fears of contracting the virus appear to have led to decreased uptake of SRH services, increased reports of intimate partner violence, and in some settings reduced access to contraception and safe abortion care. ${ }^{1}{ }^{2}$ Vulnerable populations are disproportionately affected, including young people, Indigenous peoples, as well as refugees and asylum-seekers whose safety and care is deprioritised. ${ }^{3}$ Predictions have been made about higher rates of unintended pregnancy, unsafe abortion, short interpregnancy intervals, and untreated sexually transmitted infections. ${ }^{1}$

The pandemic has also led to rapid implementation of innovations and legal and regulatory changes that have transformed and improved care for some people. New policies, practices and even enactment of laws have removed barriers to care which could otherwise take years of bureaucracy to overturn. ${ }^{4-6}$ This editorial draws on the expertise of a range of international clinicians and researchers to examine these changes to policy and practice, many of which may have lasting community benefits.

\section{CONTRACEPTION CARE}

Many countries have recognised continuity of contraception provision, particularly long-acting reversible contraception (LARC), as essential. Where infrastructure permits, there has been a significant shift to telemedicine, for instance in the United States (US), Canada, UK, France, Australia, Scandinavia, China, South Africa and Nepal. ${ }^{467}$ Some countries have been able to maintain LARC access through brief procedural visits with appropriate personal protective equipment (PPE) following a virtual consultation. In some parts of the world the rapid development of clinical guidance to permit the off-label extended use of LARC has served to support those unable to attend scheduled removal and reinsertion visits. ${ }^{47}$

Innovations include 'click and collect' policies allowing contraceptive prescriptions to be sent directly to pharmacies after 
a 'telephone/video visit' or a supply of pills to be sent to a person's home. In France patients can obtain extra supplies of their combined hormonal contraceptive pills without renewed prescriptions. The UK Faculty of Sexual and Reproductive Healthcare (FSRH) and the Society of Obstetricians and Gynaecologists of Canada have supported use of the progestogen-only pill during the pandemic, as it can be supplied to new users for up to a year without a baseline blood pressure, and both organisations support remote prescribing of an additional year's supply of the combined pill. ${ }^{47}$ In the US, one state (California) has rapidly approved drive-through contraceptive injection services and direct pharmacy provision of self-injectables, a change that might otherwise have taken years to come about. Welcome changes have also occurred elsewhere. In Lebanon, Syrian refugees can now access free contraception through local clinics, while task-sharing of contraceptive counselling and provision with nurses, midwives and community health workers has been globally recognised as an important strategy to enhance access. ${ }^{8}$

\section{ABORTION CARE}

In many countries abortion has been designated an essential service in recognition that access cannot be delayed or postponed without impacting physical and psychological well-being, but others have used it as an excuse to constrain services. In the US, for instance, some states have attempted to restrict or prohibit abortion services, although injunctions against these policies have mostly been successful. ${ }^{9}$ Such limitations to services may lead to a rise in self-managed abortions often carried out safely using online telemedicine services; however, where such services are unavailable, the risk of unsafe abortions may increase. ${ }^{1}$

The need to keep people out of hospital, and to protect both patients and clinicians from exposure to COVID-19, has accelerated a shift from surgical to medical abortion. Simultaneously, access to medical abortion has been enhanced by new policies, practices and even enactment of laws, and again, tasksharing with other mid-level healthcare providers is an important development.

While the benefits of self-managed medical abortion have been recognised for years, rapid adoption has occurred in some jurisdictions where it was previously unattainable. Abortion regulations in England, Scotland and Wales now allow home administration of both mifepristone and misoprostol supported by telemedicine, while regulatory changes have extended the upper gestational limit from 9 to 10 weeks in Finland, to 12 weeks in Scotland ${ }^{5}$ and from 7 to 9 weeks in France. New regulations in Northern Ireland do not permit mifepristone at home, but consultations can now be undertaken remotely followed by a short in-person visit.

Protocols for 'no-test/no-touch medical abortion' have been published, ${ }^{10}$ and countries such as Canada, ${ }^{4}$ where abortion is fully decriminalised and has been regulated as a publicly funded health service for over 30 years, have quickly transitioned to a virtual health model. In Britain, policies include a service model where an ultrasound scan is only undertaken if a reliable last menstrual period (LMP) cannot be provided or the history is concerning for an ectopic pregnancy. ${ }^{5}$ Similarly, while the UK's 2019 National Institute for Health and Care Excellence (NICE) guidelines obviated the need for anti-D for Rhesus-negative people undertaking medical abortion below 10 weeks, Australia and Canada also adopted this change at the start of the pandemic, and Scotland rapidly approved an extension to 12 weeks.

\section{ENSURING EVIDENCE-BASED SUSTAINABLE CHANGE}

Despite strong evidence of the safety and effectiveness of many of these practice changes, regulatory and legislative restrictions have impeded their implementation in many parts of the world. During the pandemic, the most progressive jurisdictions have consolidated existing practices to ensure access to SRH services, while others have moved swiftly to lift unnecessary regulations. However, many still lag behind or, as in the case of Poland and Hungary and some US states, are taking advantage of COVID-19 to further restrict access.

Some of the changes in SRH care ushered in during the pandemic could potentially reduce inequality of access to services in a range of settings provided that quality and safety of care can be documented. For example, telemedicine should not be blindly implemented as a cost-saving measure as it may not always lend itself well to screening for and disclosure of intimate partner violence including reproductive coercion, as conversations may be overheard or intercepted. Care should also be taken to avoid the loss of a skilled surgical abortion workforce as well as people's ability to choose the method which best suits their circumstances with a shift to medical abortion. Consumer participation in service development is essential to protect personal preferences and choices for telemedicine or face-to-face consultation, for methods of contraception, and for medical versus surgical abortion.

The current global pandemic presents an unparalleled opportunity to advance sustainable contraception and abortion care policy and services which incorporate the needs of individuals, families and communities and uphold the principles of autonomy, confidentiality and dignity.

\footnotetext{
Author affiliations

${ }^{1}$ Family Planning New South Wales, Sydney, New South Wales, Australia

${ }^{2}$ Faculty of Medicine and Health, The University of Sydney, Sydney, New South

Wales, Australia

${ }^{3}$ British Pregnancy Advisory Service (BPAS), Stratford upon Avon, UK

${ }^{4}$ Department of Family Practice, University of British Columbia, Vancouver, British Columbia, Canada
} 
${ }^{5}$ Faculty of Public Health and Policy, London School of Hygiene and Tropical Medicine, London, UK

${ }^{6}$ Population Family and Reproductive Health, Johns Hopkins University Bloomberg School of Public Health, Baltimore, Maryland, USA

${ }^{7}$ CESP Centre for Research in Epidemiology and Population Health, INSERM (Institut National de la Santé et de la Recherche Medicale), Villejuif, France

${ }^{8}$ Department of Women's and Children's Health, Karolinska Institute, Stockholm, Sweden

${ }^{9}$ Karolinska University Hospital, Stockholm, Sweden

${ }^{10}$ Stanford University School of Medicine, Stanford, California, USA

${ }^{11}$ Faculty of Wellbeing, Education and Language Studies, The Open University, Milton Keynes, UK

${ }^{12}$ Department of Obstetrics and Gynaecology, University of Hong Kong, Hong Kong, Hong Kong

${ }^{13}$ LBJ School of Public Affairs, The University of Texas at Austin, Austin, Texas, USA

${ }^{14}$ Women's Health, Neonatology and Paediatrics, Royal Prince Alfred Hospital, Sydney, New South Wales, Australia

Twitter Deborah J Bateson@DrDebBateson, Wendy V Norman @wvnorman and Lesley Hoggart @drhoggart

Acknowledgements We acknowledge the invaluable contributions of Dr Stephen McCall and Professor Sharon Cameron.

Contributors DJB conceived and wrote the initial draft with input and editing from KIB. PAL, WVN, CM, KGD, PDB, LH, HWRL and ARAA provided key information and edits on each draft.

Funding The authors have not declared a specific grant for this research from any funding agency in the public, commercial or not-for-profit sectors.

Competing interests None declared.

Patient and public involvement Patients and/or the public were not involved in the design, or conduct, or reporting, or dissemination plans of this research.

Patient consent for publication Not required.

Provenance and peer review Not commissioned; externally peer reviewed.

This article is made freely available for use in accordance with BMJ's website terms and conditions for the duration of the covid-19 pandemic or until otherwise determined by BMJ. You may use, download and print the article for any lawful, noncommercial purpose (including text and data mining) provided that all copyright notices and trade marks are retained.

\section{ORCID iDs}

Deborah J Bateson http://orcid.org/0000-0003-1035-7110
Patricia A Lohr http://orcid.org/0000-0003-1862-5730

Wendy V Norman http://orcid.org/0000-0003-4340-7882

Caroline Moreau http://orcid.org/0000-0002-8637-6249

Lesley Hoggart http://orcid.org/0000-0002-4786-7950

Hang-Wun Raymond Li http://orcid.org/0000-0002-7957-7798

Kirsten I Black http://orcid.org/0000-0003-0030-2431

\section{REFERENCES}

1 Riley T, Sully E, Ahmed Z, et al. Estimates of the potential impact of the COVID-19 pandemic on sexual and reproductive health in low- and middle-income countries. Int Perspect Sex Reprod Health 2020;46:73-6.

2 International Planned Parenthood Federation (IPPF). COVID-19 impact, 2020. Available: https://www.ippf.org/ covid19

3 Kluge HHP, Jakab Z, Bartovic J, et al. Refugee and migrant health in the COVID-19 response. Lancet 2020;395:1237-9.

4 Society of Obstetricians and Gynecologists of Canada. SOGC COVID-19 resources, 2020. Available: https://sogc.org/en/ content/COVID-19/COVID-19.aspx? COVIDResources $=2$

5 Royal College of Obstetricians and Gynaecologists. Coronavirus (COVID-19) infection and abortion care. London: Royal College of Obstetricians and Gynaecologists, 2020.

6 Royal Australian and New Zealand College of Obstetricians and Gynaecologists (RANZCOG). Coronovirus (COVID-19): information hub, 2020. Available: https://ranzcog.edu.au/news/ covid-19-anti-d-and-abortion

7 Faculty of Sexual \& Reproductive Healthcare (FSRH). Essential services in sexual and reproductive healthcare, 2020. Available: https://www.fsrh.org/fsrh-and-covid-19-resourcesand-information-for-srh/

8 World Health Organization (WHO). Task sharing to improve access to family planning/contraception, 2017. Available: https://apps.who.int/iris/bitstream/handle/10665/259633/ WHO-RHR-17.20-eng.pdf;jsessionid=1828E527A66369A1 E491379C7519801B? sequence $=1$ [Accessed 15 Jul 2020].

9 Carter D. Abortion access during COVID-19, state by state, 2020https://rewire.news/article/2020/04/14/abortion-accesscovid-states/

10 Raymond EG, Grossman D, Mark A, et al. Commentary: no-test medication abortion: a sample protocol for increasing access during a pandemic and beyond. Contraception 2020;101:361-6. 